\title{
La derrota sandinista y el nuevo cuadro regional
}

\author{
Gabriel Gaspar Tapia
}

Como uno de los casos de mayor sorpresa electoral, cuando todos los vaticinios auguraban un triunfo de Daniel Ortega, el escrutinio arrojó desde los primeros momentos un amplio triunfo para la candidata de la Unión Nacional Opositora, dona Violeta Barrios de Chamorro.

Las elecciones nicaragũenses no fueron las únicas en la región centroamericana, en los primeros dias de febrero los costarricenses acudieron a las urnas y otorgaron el triunfo al candidato del Partido Unidad Social Cristiana, Rafael Angel Calderón Fournier. En noviembre de 1989, en las elecciones hondurenas, Rafael Leonardo Callejas, abanderado del partido Nacional, derrotó a su vez a Flores Facusse, candidato del partido liberal.

A estos resultados, le podemos sumar la victoria de ARENA sobre la democracia cristiana salvadoreha en marzo de 1989, que permitio acceder a la primera magistratura a Alfredo Cristiani. Para completar el cuadro, es preciso advertir que en noviembre del presente ano, los guatemaltecos acudirán a las urnas para elegir al sucesor de Vinicio Cerezo. De esta manera, en poco más de ano y medio, la totalidad de los paises de la región han llevado a cabo procesos electorales y como producto de ellos, se ha operado una significativa modificación del cuadro de fuerzas regional.

En las presentes notas queremos abordar el examen de las repercusiones que para el conjunto de la región tendrán estos procesos electorales. Para ello trataremos de resaltar, más que un examen de cada proceso nacional, los efectos globales. En una primera apro- 
ximación queremos referirnos a los siguientes:

A) La consolidación de sistemas políticos basados en elecciones competitivas para designar a los gobernantes.

B) La emergencia de una derecha renovada en la región centroamericana portadora de un proyecto de reorganización económica y que reivindica la democracia política.

C) La constitución de un bloque de paises aliados de EE.UU. con mayor legitimidad.

D) El predominio de las opciones pacifistas y democratizadoras por sobre opticas de transformación social.

Queremos analizar estos efectos globales por separado, sin detenerlos en el examen particular de cada caso, para luego intentar una evaluación general.

\section{A. La consolldación de sistemas políticos}

A comienzos de la crisis regional, y habria que agregar que como práctica de muchas décadas, la totalidad de los países centroamericanos - con la excepción de Costa Rica- se encontraban gobernados por diferentes regimenes militares. A comienzos de los noventa la situación pareciera haber cambiado, y también cabría agregar que no se trata sólo de una tendencia regional sino que se generaliza para el resto de latinoamerica.

En efecto, a comienzos de los noventa, salvo el gobierno haitiano, todos los gobernantes actuales han surgido de consultas electorales.1

Pero, se podria contraargumentar, en la mayoria de los paises centroamericanos, siempre han habido elecciones, es más, la mayoría de los gobiernos militares utilizaban el recurso electoral apoyándose en partidos oficiales que merced al fraude y la intimidación, pretendian dar un barniz democratizador a los gobiernos oligárquicos.

Lo anterior es cierto, las elecciones no son nuevas en centroamérica. Qué es lo nuevo entonces? En nuestra opinión to nuevo pareciera radicar en que se propicia que participe la oposición, que se cuenten los votos, $y$, que en caso de que gane la oposición, ésta pueda acceder al gobierno. O sea, que sea real la alternancia.

La alternancia en centroamerica es un hecho, a la fecha, en esta ronda electoral de fines de los ochenta y comienzos de los noventa, en todas las elecciones ha triunfado la oposición. Es más, esta es una tendencia que también se ha corroborado en el resto de la región latinoamericana. ${ }^{2}$ 
Pero la afirmación anterior debe ser matizada. Si bien es posible encontrar altemancias efectivas en los recientes procesos electorales cabria preguntarse si en todos ellos, han podido participar todos los sectores políticos. Un examen objetivo nos diria que para los casos de El Salvador y Guatemala, la respuesta es negativa, vale decir, no todos pueden participar, se trata en concreto de las fuerzas que hoy se identifican $\infty$ las organizaciones insurgentes. Se podria argumentar que no participan porque no quieren participar, porque se trataria de organizaciones que profesan ideologias no democráticas, extremistas, y que además descartan su participación electoral. Pero lo cierto es que tanto el FMLN salvadoreno como la URNG guatemalteca han incorporado a sus plataformas programáticas, la solución política negociada, $e$ inclusive, han sugerido sus participación electoral si es que se dan normas minimas que garanticen un proceso justo. ${ }^{3}$

Si la altemancia va acompanada de un esfuerzo por facilitar la incorporación al sistema político, el mayor mérito en esta materia, 10 encontramos en el caso nicaragüense; el sandinismo está demostrando que es democrático en las buenas y también en las malas. Pueden las oligarquias guatemaltecas y salvadorenas demostrar lo mismo?. De esta manera, un buen indicador respecto al grado de democratización que expresan estos procesos eleccionarios, to da el examen de si el sistema permite la incorporación plena de todas las fuerzas políticas. Al respecto, es necesario diferenciar.

En los casos de Costa Rica y Nicaragua, es posible observar que en los procesos electorales participan las principales fuerzas políticas del pais." En un extremo opuesto encontramos a la situación guatemalteca y salvadorena, alli, tanto el FMLN como la URNG, y en general, el espectro izquierdista del arco político, no sólo carece de posibilidades de participación, sino que es perseguido sistemáticamente. En una situación intermedia encontramos el caso hondureno, dado que alli, si bien participan en el proceso electoral las principales fuerzas (nacionales y liberales), el resto de ellas, desde el moderado PINU hasta la izquierda, no tiene mayores facilidades para consolidar su presencia. La circunstancia de que la izquierda hondurena sea pequena, no invalida nuestra observación.

De esta manera, la democracia que nace en Centro América, para muchos paises, tiene el signo de la "baja intensidad" como tan acertadamente to ha calificado Edelberto Torres-Rivas. En otras palabras, la consolidación de sistemas políticos que se basan en elecciones para elegir a sus gobernantes, no puede interpretarse linealmente como sinónimo de democratización. En algunos casos, la 
liberación politica que se observa, tiene como fundamento la necesidad de elevar los niveles de legitimación estatal a fin de asegurar la preservación del sistema económico-social.

Esta es una discución que no por antigua, esta totalmente agotada. Si entendemos a la democracia no como un método sino como una condición social, entonces tenemos que impugnar el grado de democratización que pueda darse en sociedades donde no se permite el pluralismo, se persigue a los disidentes, se violan los derechos humanos y el poder civil no logra subordinar al poder militar, los cuales, entre otros aspectos, son características de la vida cotidiana de muchos paises centroamericanos, a pesar de que en ellos se lleven a cabo procesos electorales con rigurosa regularidad desde hace algunos antos.

En el saldo positivo de este proceso, tenemos que la idea de la confrontación de ideas más que de fuerza, la preocupación por el consenso, el interés por convencer al electorado, son sintomas que van a parejas de los procesos electorales. Por supuesto, la creciente tecnificación de estos procesos, de la utilización de sofisticadas técnicas de marketing politico, hacen necesario legislar a fin de asegurar nomas igualitarias de participación, sobre todo en los medios de comunicación. De to contrario quienes posean más recursos económicos tendrán ventajas indudables para su participación.

\section{La emergencla de una derecha renovada}

Otro aspecto que sobresale en esta coyuntura regional, es el ascenso de fórmulas políticas que se identifican con la economia de mercado. O sea, el triunfo de la derecha, que a veces se identifica tal cual, o en otras se define como "centro-derecha".

En efecto, tanto ARENA, como el PUSC y el partido nacional hondureno constituyen las principales expresiones a la derecha del arco político de sus respectivos paises. Pero esta afimación puede ser ampliada. Si bien es cierto que las tres fuerzas aludidas estan a la extrema derecha del arco político-ideológico, no es del todo exacto, caracterizarlas como conservadoras.

En nuestra opinión, en el último tiempo es posible observar que ha madurado un proceso de recomposición de la representación política de las clases dominantes centroamericanas. ${ }^{\circ}$ En ese proceso, el bloque dominante ha asumido un nuevo perfil que en lo básico se expresa en asumir las tesis del neoliberalismo como doctrina económica, de enfrentar las tareas de construir un sistema político basado en elec- 
ciones competitivas, en medio de una Kogica de guerra frla en relación a las relaciones intemacionales.

Esta propuesta quizás no es tan original como para permitir la denominación de "nueva derecha", pero sl es diferente de la propuesta que levantaba la derecha centroamericana antes de la crisis. En efecto, salvo destacadas excepciones, los partidos de derecha, los gremios empresariales y la intelectualidad del sistema, hasta la década de los setenta, no pretendian mayores modificaciones al sistema de la hacienda agroexportadora tradicional, nunca se preocuparon por la democracia y, se acomodaron a la convivencia con regimenes militares que les garantizaban el orden social necesario para desarrollar sus actividades.

Este último no es el perfil de la campana de Cristiani, ni de Calderón ni de Callejas. En lo referente a la UNO nicaragüense, si bien representa una coalición abigarrada donde hasta hay comunistas, es indudable que en su seno, son los sectores económicamente dominantes quienes tiẹnen una posición de dirigencia.

Este proceso de recomposición de la representación política de las clases dominantes ha ido generalmente acompanada de una politización ascendente de los gremios empresariales, donde los sectores propietarios centroamericanos se parapetaron defensivamente en los primeros anios de la crisis. Al respecto las movilizaciones que el CACIF guatemalteco y la ANEP salvadorena promovieron en contra de los gobiernos democristianos en sus paises, son una buena expresión de esta aludida politización empresarial.

En el contenido de esta activación del sector privado, destaca la demanda por abandonar todo signo de estatismo en la conducción oconómica. En ello engloban a las propuestas económicas de la democracia cristiana, a las de economia mixta como la nicaragũense, y por supuesto, a las tesis de economias centralmente planificadas como las que sugiere la izquierda. El nuevo paradigma es la diversificación de exportaciones, la liberalización de la economia, entendida como su privatización, promoviendo para ello lo que se ha conocido como el "ajuste estructural". Las experiencias a seguir serian las de los paises del sudeste asiático y la economia chilena bajo Pinochet.

Es muy discutible que este nuevo paradigma neoliberal sea capaz de posibilitar un desarrollo capitalista partiendo de las actuales condiciones de las economias centroamericanas. Al respecto, atendiendo a los logros de estabilización, crecimiento y diversificación alcanzados por la economia chilena en los últimos anos, que los intelectuales del 
saliente regimen militar atribuyen exclusivamente a la política económica aplicada por los discipulos chilenos de Friedman, cabe hacer más de un comentario.

Una difundida argumentación crítica es aquella que hace referencia al llamado "costo social" que acompaña a este tipo de políticas, pero no queremos aqui detenernos en ella, sin que ello signifique negar su importancia en materia no sólo de equidad social sino también en sus repercusiones en materia de estabilidad política. Lo que nos llama la atención, es la manera acrítica en que buena parte del sector privado centroamericano ha hecho suyas las tesis del neoliberalismo, sin detenerse a considerar las bases de las cuales partirian en este "ajuste". Y aqui cabe volver al examen de la situación chilena.

En Chile, al iniciarse el gobiemo militar, merced a dos medidas adoptadas por el gobierno socialista de Salvador Allende, existian condiciones que allanaron el camino de la modernidad económica. Esas eran la nacionalización del cobre y la reforma agraria.

Merced a la primera, el Estado se apropio del excedente generado por el principal recurso exportador del pais, lo cual libró a la conducción económica chilena de un problema cuasi insoluble de la mayoria de las economias latinoamericanas: como redistribuir en el conjunto de la economia, las divisas obtenidas por el sector externo, 0 , cómo convencer a los propietarios - sean mineros o agroexportadores- que parte de sus ganancias debian de servir para diversificar el resto del aparato productivo.

Por su parte, la reforma agraria chilena, iniciada por el democristiano Eduardo Frei y profundizada en los tres años del gobierno de la Unidad Popular, acabó con el latifundio. Pinochet privatizó las cooperativas reformadas, pero no reconstnyó la vieja hacienda. Surgió asi una extendida capa de medianos empresarios agricolas de alta productividad, que basan su acumulación en el uso intensivo de la tierra, a diferencia de los latifundistas de antaño, cuyos principales recursos productivos eran la extensión de la tierra y la baratura de la fuerza de trabajo. Ha sido esta capa de nuevos propietarios agricolas, verdaderos empresarios, surgidos del fin del latifundio, quienes han protagonizado la diversificación agrícola chilena de estos años, en especial, de su sector fruticola exportador.

Aplicar la receta chilena a la situación de centroamerica supondria que las clases dominantes estarian dispuestas a aceptar, como condición previa para modernizar el aparato productivo, nacionalizaciones del café, del algodón o de complejos fruticolas exportadores, según sea 
el caso. $Y$ además, aceptar llevar adelante una reforma agraria que liquidase a la hacienda improductiva. Para cualquier observador con alguna distancia, un escenario de esa naturaleza pertenece virtualmente al mundo de la ciencia ficción.

Pero, independientemente del grado de viabilidad que tenga un ajuste de tipo de neoliberal para las economias centroamericanas, 10 cierto es que, ante los convulsos sucesos de Europa del Este, y la caótica situación económica latinoamericana, las tesis del liberalismo económico adquieren una particular solidez ideológica, en medio de un desconcierto generalizado de parte de todos aquellos que propugnan diferentes formas de intervención estatal.

A comienzos de la crisis centroamericana se levantaba con fuerza un proyecto fundacional de corte nacional popular, que reivindica una profunda reorganización de la economía y un cuestionamiento del sistema político. Era el proyecto de "las izquierdas", sean las armadas o las no armadas, las con arrastre de masas o las marginales. Pero no era el único proyecto fundacional, a inicios de los ochenta, la opción de corte democristiana también adquirió una particular fuerza en la región, combinando democratización con reformas y compartiendo con la izquierda su crítica al estado oligárca.

En ese cuadro, la oligarquia centroamericana carecia de un proyecto globalmente alternativo, y menos aún de un proyecto que pudiese argumentarse como más justo, más eficiente y más modemo que los otros propuestos. Hoy, diez años después, la región conoció los límites y las posibilidades de la democracia cristiana, también conoció los costos de un proceso de transformación social como el que encabezaron los sandinistas, supo de la voluntad implacable de la administración norteamericana por hostilizar cualquier alternativa que considerase contraria a sus intereses. En dicho contexto, la derecha se rearmo ideológica y programáticamente y hoy cosecha.

Más, en la nueva propuesta de los sectores dominantes, de sus partidos políticos e intelectuales, ocupa un lugar destacado la reivindicación de la democracia. Pese a que la concepción de democracia que fluye de esta propuesta esta circunscrita a las dimensiones del régimen político, esto constituye un avance de proporciones en relación a la apatía, cuando nó indiferencia, que las clases dominantes manifestaron en el pasado respecto a la tarea democrática.

Dado su comportamiento histórico, con la destacada excepción del caso de Costa Rica, la derecha centroamericana tiene que demostrar que su alegato democrático no es sólo un recurso electoral, o un 
mecanismo para legitimar su dominación. Por el contrario, el sandinismo (y por su intermedio la izquierda centroamericana) ha demostrado con su conducta a la fecha, que su convicción y su comportamiento democrático son sólidos. Podrán las oligarquias centroamericanas emular al sandinismo en este tipo de actitud? Podria por ejemplo ARENA convocar a elecciones dando garantias a todos los sectores, amnistiando a los presos políticos, flexibilizando la legislación electoral, permitiendo observadores internacionales, sin exigir al mismo tiempo el desarme previo de la insurgencia?

\section{La conformación de un nuevo bloque de allados de EE.UU.}

En los inicios de la crisis, la administración norteamericana tenia un problema: sus más fieles aliados centroamericanos estaban muy deslegitimados.

Esta circunstancia se agravaba más cuando se contrastaba con los objetivos de la política centroamericana que profesaba la Casa Blanca: el defender la democracia en la región, amenazaba por el expansionismo soviético y sus aliádos.

Resultaba muy contradictorio defender la democracia apoyando a las dictaduras que poblaban la región a fines de la década de los setenta. Esto no era sólo un problema para la diplomacia del Departamento de Estado, también era una grave dificultad convencer a los congresistas, a los formadores de opinión pública, y a la ciudadania en general, que al aumentar la ayuda a los militares centroamericanos se estaba defendiendo a la democracia. Si la Casa Blanca queria establecer un consenso interno mínimo para su operación centroamericana, debía disponer de aliados más legitimados.

De esta manera, es posible entender que la preocupación de la Casa Blanca por promover procesos electorales competitivos y alternativas efectivas, era una necesidad vital para acompanar a su estrategia contrainsurgente. Pero no queremos exagerar, dado que no falta la crítica de izquierda que tiende a ver que todo el esfuerzo por establecer liberaciones políticas forma parte de complejos y estatutos planes del Pentagono. Desde todo punto de vista, es preferible, en nuestra opinión, una derecha que haga mitines, que trate de convencer por la propaganda, que presente programas, a una derecha que use escuadrones, o que queme cosechas de cooperativas 0 asesine alfabetizadores 0 catequistas.

Tampoco hay que entender que la generalización de procesos electorales en la región sea resultado exclusivo de los afanes de la 
Casa Blanca por disponer de aliados legitimos. La democratización política es una demanda de vastos sectores de las sociedades centroamericanas, desde antes de la crisis. No sólo es una demanda proveniente de sectores ubicados a la izquierda, es una demanda de los social cristianos, de los social demócratas, de las iglesias, del movimiento sindical, de las universidades, de los intelectuales democráticos, entre otros.

Pero el balance que queremos destacar, no es sólo el tipo de sistema político que se está instaurando en los paises centroamericanos, sino que como resultado de las justas electorales, se han constituido un conjunto de gobiernos que se perciben a si mismos como aliados de EE.UU. Al inicio de la década de los noventa, la administración norteamericana dispone de un conjunto de aliados legitimados no sólo ante la comunidad internacional sino que en buena medida, legitimados al interior del sistema político norteamericano.?

Más, no es posible sacar de esta anterior afirmación la percepción de que se trata de un bloque homogéneo, dispuesto a respaldar todas y cada una de las acciones que proponga la Casa Blanca. En materia de pacificación regional, de desarme, y de tratamiento a las FF.AA. es posible advertir diferencias entre los nuevos gobiernos que emergen.

En relación a la forma de percibir la pacificación, en un extremo tenemos al gobierno del PUSC costarricense, que en to fundamental buscará llevar adelante el espiritu de Esquipulas, es decir, buscando formulas parecidas a la nicaragũense. En el otro extremo tenemos al gobierno de ARENA que entiende hasta la fecha pacificación como rendición de la insurgencia o guerra total. Estas diferencias indudablemente repercutiran a la hora de que EE.UU. defina un curso de acción luego de la transición en Nicaragua.

Lo mismo podemos decir en relación al ya insinuado tema del desarme general en la región. Esta perspectiva seria de extrema utilidad para el gobiemo de Violeta Chamorro, de Calderón, inclusive para los gobiernos de Honduras y Guatemala (no asi para los ejercitos de estos últimos paises). En esta convergencia de intereses nunca podria respaldar un planteamiento de esta naturaleza sería el gobierno salvadoreno, salvo que llegase a un acuerdo global con la insurgencia en promover una salida política.

Como se vé. EE.UU. puede congratularse de disponer hoy de aliados legitimados en la región, pero cometeria un grave error si los confundiese con aliados incondicionales para cualquier política.

En los párrafos anteriores, hermos subrayado la posibilidad de dis- 
crepancias entre la política norteamericana con sectores conservadores de corte civilista. Pero también se abre un campo de eventuales contradicciones entre los norteamericanos y los "duros" de la derecha.

En efecto, en la mayoria de los procesos electorales reciente, y no sólo es una peculiaridad de centroamerica, es posible advertir la emergencia de un perfil "populista" que asumen sectores de extrema derecha. El posicionamiento actual del mayor Roberto D'Abuisson es un ejemplo de esto, en su opinión, los "bobbies" que se han enquistado en el gobierno, que hablan y piensan en ingles, son insensibles a los sentimientos de la población, adoptan políticas económicas que amenazan a los hombres de trabajo, y para colmo de males, estarlan dispuestos a negociar con los terroristas. Este sector, más explicable por sus posiciones ideológicas que atribuible a identidades productivas, teme a lo que denominan "el sindrome de Carter", es decir, que a raiz de consideraciones de política interna, los norteamericanos llegado el caso, estarian dispuestos a sacrificar a sus aliados más leales.

Cabe destacar que esta percepción de "abandono latente" también es muy fuerte al interior de las fuerzas armadas, sensibles a este tipo de discurso, lo cual explica que por lo general, los "duros" del ejercito, tienden a identificarse con la ultraderecha en una crítica ultranacionalista respecto a los EE.UU. lo cual no impide el que en determinados momentos, asuman posiciones de corte populista. Los autodenominados "oficiales de la montana" del ejercito guatemalteco, quienes se firman como "Juan Arena" en El Salvador y los sectores más ultras de las fuerzas armadas hondurehas representan a esta tendencia.

A nivel latinoamericano podemos encontrar rasgos comunes con esta corriente, en los llamados "carapintadas" de las fuerzas armadas argentinas, dirigidas por el mayor Rico y el coronel Seineldin. En el caso de Chile tenemos a la oficialidad fanática que hasta la fecha ha aceptado a reganadientes la transición democrática, no es casual que aparte de los repudios de la juventud izquierdista unguaya, la única contramanifestación que sufrio el vicepresidente Quayle en su reciente viaje a sudamérica, provino de parte de algunos centenares de pinochetistas furiosos que acusaban al gobiemo norteamericano de haber influido en la derrota de la dictadura. ${ }^{\circ}$

En el caso centroamericano, además de estas contradicciones de tipo político-ideológico que eventualmente puede tener o ha tenido el gobierno norteamericano con la ultraderecha, y en especial con el sector duro de las fuerzas armadas, existen dos puntos de conflicto que son muy dificiles de digerir para los norteamericanos. Estos son la 
violación de los derechos humanos y el involucramiento con las redes de narcotráfico.

Ambos temas son difíciles de rastrear a profundidad, pero para nadie es un misterio que hay vasos comunicantes entre los escuadrones de la muerte y los servicios de seguridad. El reciente asesinato de los jesuitas salvadorenos ha permitido sacar a la luz la sordidez de estas prácticas, pero desgraciadamente no es un caso único ni tampoco novedoso para la mayoría de la población centroamericana.

El narcotráfico está en parte ligado a quienes controlan espacios aéreos, aduanas, fronteras y afines. A la fecha hay indicios que vinculan directamente a sectores de la oficialidad hondurena con los narcos, lo mismo con oficiales salvadoreños, demás esta agregar el caso de la contra ya puesto de relieve con las revelaciones del caso Iran-Gate. El control del narcotráfico interesa y preocupa a la mayoria de la población norteamericana y no puede su gobierno aparecer empleándose a fondo como en el caso de Panamá y Noriega, y al mismo tiempo, hacer la vista gorda con otros militares latinoamericanos, sólo por el hecho de que estos últimos, eventualmente combaten contra comunes enemigos políticos. ${ }^{10}$ Esta circunstancia marca un limite para el apoyo norteamericano: cualquiera fuerza de derecha que se involucre en el narcotráfico, por más prooccidental que sea, por más anticomunismo que profese, a la larga tendrá dificultades con las agencias norteamericanas.

\section{El surgimlento de un nuevo paradlgma, la paciflcación y la democratización.}

Hemos querido para dejar al final esta última reflexión que las elecciones nicaragüenses nos provocan. En los comienzos de la década pasada, existía un relativo predominio en la mayoría de la región, de las ideas del cambio social. Puntos más, puntos menos, buena parte de la sociedad asimilaba como válidas las tesis que cuestionaban a la sociedad oligárquica, tradicional e ineficiente en lo económico y antidemocrática en lo político, amen de injustas en lo social.

El triunfo de la revolución sandinista proporcionó un enorme impulso a estas concepciones, el incremento de la movilizacion política y social en El Salvador y Guatemala fueron expresión del nuevo nivel que alcanzaba la crítica social. Esta crítica a la vieja sociedad oligárquica era además compartida por instituciones académicas, por importantes sectores de la iglesia católica y reforzada por los diagnósticos de organismos internacionales como la CEPAL, la UNESCO y el PNUD. 
Retomando lo sehalado anteriormente, podriamos sintetizario en el hecho de que, desde el punto de vista de la ideas, el liberalismo se encontraba a la defensiva y los proyectos políticos que se identificaban con su crítica, eran prodominantes. Hoy no es necesariamente asi, pero nuevamente hay que cuidarse de exagerar.

Hoy en dia se argumenta en algunos sectores que en Centro América habria concluido el ciclo de las revoluciones y que se estarla ingresando al ciclo de la democracia y las elecciones. Con más prudencia, otros autores se aproximan a la idea de que con la derrota electoral de los sandinistas, se completa todo un periodo en la historia latinoamericana que se inició con la revolución cubana."

Son muchos los que se apresuran a enlazar el triunfo de la UNO con los fenómenos de Europa del Este, todos serian expresión de un fenómeno universal: el derrumbe del socialismo. ${ }^{12}$ Pero en este tipo de interpretaciones, cargadas de voluntarismo, se reedita por la derecha el mismo sindrome de los "catastrofistas" de izquierda, que desde hace décadas, ante cada tropiezo del capitalismo, se apresuran a hablar de crisis general y última. ${ }^{13}$

Obviamente, el clima ideológico de las sociedades centroamericanas ha evolucionado en estos anos. Para analizar esta evolución, nos inclinamos por la vieja tesis, de que son los procesos sociales los que generan pensamiento social. Entonces cabe preguntarse qué ha pasado en estos años en Centro América que ha llevado a un segundo plano, inclusive al rechazo en grandes sectores, de las tesis de la transformación social.

Este es un tema de largo aliento, y aqui sólo queremos enunciar algunas hipótesis, partiendo del reconocimiento obvio de que la mayoria de la región ha vivido una situación de guerra. Esto nos provoca muchas interrogantes respecto al impacto que provoca un conflicto prolongado, pero hoy sólo queremos detenernos en la que consideramos de mayor implicancia en relación a los recientes electorales.

La presunción principal podriamos enunciarla de la siguiente manera: la prolongación de la crisis, en particular de los efectos de la guerra sobre la población, ha alimentado una nueva idea fuerza, cuya solución para numerosos sectores de las sociedades afectadas, adquiere la primera prioridad. Esta nueva idea fuerza es la voluntad nacional de la paciticación.

Desde este punto de vista, todo aquello que sea percibido como factor de continuidad del conflicto tiene necesariamente que ser visto como costoso. En determinados casos - como el nicaragüense- la 
persistencia en los proyectos de transformación social, tendría como consecuencia inevitable, no querida pero segura, la prolongación de la guerra.

Desde este punto de vista, estarla en disputa por parte de las diversas fuerzas políticas, el liderazgo de la pacificación. Aquella que sea capaz de ofrecer a la población, una altemativa viable, cercana y real de paz, puede nuclear mayorías en tomo suyo. Esto no debe entenderse necesariamente como un triunfo ideológico del liberalismo en todas y cada uno de los casos, sino con el agotamiento de sociedades que han sufrido más anos de guerra que los que sufrieron los pueblos de Europa en la Segunda Guerra Mundial.

Esta voluntad pacifista en el caso controamericano va unida a una idea que cobra fuerza en toda la región latinoamericana, la idea de la democracia. No faltará quien con mucha razón recuerde que al respecto habría que precisar "de qué democracia hablamos", pero aún asumiendo la validez de dicha observación, nos inclinamos a considerar como muy positiva que la demada de paz vaya en la mayoría de los casos asociada a la vigencia de formas de gobierno basadas en el sufragio. No está demás recordar que la demanda de orden y estabilidad en muchos casos ha impulsado a legitimar formulas de gobiemo autoritarias. En nuestra opinión éste no es el caso del itsmo centroamericano.

\section{Notas finales}

A la fecha de cierre de estas notas, se han acentuado importantes procesos en el plano internacional, cuyo desarrollo enmarca a todo el acontecer mundial.

La victoria de la derecha en las elecciones de la RDA (otra "sorpresa" electoral) sumado a los vaivenes de la situación interna de la URSS son procesos de una magnitud tal, que compararán durante mucho tiempo la atención de los principales actores internacionales.

En ese cuadro, en la región centroamericana se ha operado un significativo proceso de recomposición de los equilibrios políticos, en esta oportunidad hemos querido subrayar algunos de los efectos globales que los recientes procesos electorales han generado, pero aún estan pendientes dos procesos nacionales cuyo decenlace puede provocar alteraciones a lo aqui expuesto.

Estos procesos son la transición nicaragüense y las negociaciones de paz en El Salvador.

En el caso de la transición en Nicaragua, buena parte de este 
proceso estará pendiente a la solución final del problema de la contra. Mientras no se desarme, el EPS tendrá fuertes argumentos para justificar su autonomia profesional. Mal que mal, ninguna fuerza amada en el mundo puede tolerar la existencia de una fuerza irregular que cuestione las bases del sistema político que aquella debe defender. Pero esto puede llevar a un callejón sin salida si la contra aduce argumentos similares -que condiciona su desmovilización a un proceso similar del EPS-. Más, lo que las elecciones nicaragũenses también demuestran, es que la inmensa mayoria de las fuerzas politicas de dicho pais aceptaron la validez y legitimidad del sistema político vigente. Sumado a lo anterior, cabría agregar que la unanimidad de los observadores extranjeros atestiguaron que merced a ese sistema político, pudieron expresarse con libertad todas las fuerzas que participaron.

En definitiva la suerte de la contra dependera en gran medida de la actitud que frente a ella adopte el gobierno norteamericano, su principal sustento. En lo que respecta a los gobiemos centroamericanos, la aplicación rigurosa de los diversos acuerdos de las Juntas de Presidentes, permitiria reconocer la legitimidad del sistema político nicaragüense.

El otro caso es más complejo, la pacificación en EI Salvador es verbalmente un consenso de la mayoria nacional, pero nuevamente es un consenso equivoco. ARENA y su gobierno entiende por pacificación que el FMLN entregue las armas y se transforme en partido político, pero la enorme ofensiva de noviembre de 1989 demostró a todo el mundo la fuerza militar de la guerrilla, lejana a una situación de precariedad que la obligará a rendirse. EI FMLN propone una pacificación como resultado de un proceso, que según sus últimas propuestas, permita depurar al ejército de los sectores involucrados en las violaciones a los derechos humanos y asi se garantice un proceso de democratización. Entre medio de ambas opciones, hay un vasto número de propuestas mixtas que levantan las restantes fuerzas políticas salvadorenas.

En nuestra opinión, el problema es que toda negociación medianamente seria, inevitablemente afectaria a dos actores políticos: las fuerzas armadas y el FMLN. Las primeras verian reducida su presencia en el sistema político y afectados su tamaño y composición. EI FMLN por su parte, deberia desaparecer.

Para cuál de las dos fuerzas son más impagables estos costos? Nos inclinamos a pensar que los más perjudicados pueden ser los sectores "duros" de las fuerzas armadas. Ellos saben que en cualquier negociación, van a ser negociados. 
EI FMLN en cambio es una fuerza político-militar, que persigue determinados objetivos políticos, susceptibles de desarrollarse también por medios no armados. Además, la insurgencia advierte que si bien hoy está en la cúspide de su poderío militar, no ocurre lo mismo con su poderío político, por to mismo, deben traducir con urgencia su fuerza militar en fuerza política. Por ello, aunque costoso, su eventual desarme a cambio de modificaciones sustantivas al sistema politico, que entre otras cosas le permita presentarse como contribuyente decisivo de una eventual democratización, no es un horizonte inaceptable para sus mandos y combatientes.

Pero con esta misma lógica, es de suponer que los "duros" de las FF.AA. harán to posible y lo imposible para torpedear cualquier negociación de paz, sea quien sea el mediador, tarea que hoy recae en el Secretario General de las ONU. Los asesinatos de líderes pacifistas y democráticos son ejemplo del nivel de violencia y efectividad que puede alcanzar la acción de este sector. ${ }^{14}$

Dada la autonomía relativa de muchos actores políticos salvadorefios respecto al quehacer internacional, nos inclinamos a pensar que aunque el resto de Centro América pueda avanzar hacia diversos grados de distención del conflicto, en El Salvador proseguirá la polarización, transformándose de esta manera, en un nuevo epicentro de la crisis regional.

De esta manera, con la consolidación relativa de nuevos sistemas políticos, en cuyo seno a la fecha ha logrado perfilarse una renovación de las fuerzas de derecha, y en el marco ideológico de una demanda mayoritaria de pacificación y democratización, Centro América se asoma a una nueva década.

México D. F. 19 de marzo, de 1990.

\section{NOTAS}

1. Cabe precisar que con esto no estamos extendiendo un certificado de transparencia electoral a todos los procesos que se han desarrollado en la región, ni tampoco es posible contar como gobernante democrático a un gobernante, como el panameño Endara, que toma posesión de su cargo en una base del ejército que invade a su país.

2. La afirmación anterior es cierta, salvo el caso del triunto del partido colorado paraguayo, que logró elegir al general Rodríguez con más del $70 \%$ de los votos, en todos los comicios del pasado año se impuso la oposición: los peronistas en Argentina, Aylwin en chile, los blancos con 
Lacalle en Uruguay, Collor en Brasil. Y para este año nadie piensa que el APRA pueda triunfar en las elecciones de mayo en Perú.

3. En efecto, tanto en la ronda de negociaciones entre la URNG y el gobierno de Vinicio celebradas en Madrid en el mes de octubre de 1987; como en las diversas propuestas de paz de la guerrilla salvadoreña, ambas fuerzas plantean su participación electoral, inclusive, su desarme, si se realizan procesos electorales con garantías mínimas para todos los participantes.

4. Podrla objetarse que en el caso nicaragüense no estuvo presente la contra, pero ella se ha definido como una fuerza militar y no partidaria. Al mismo tiempo, fue expresa su simpatía por la candidatura de la UNO.

5. Hacemos alusión a la distinción de concepciones de la democracia que formulara hace algún tiempo Umberto Cerroni.

6. Al respecto, hemos desarrollado un seguimiento de este proceso para el caso salvadoreño on "El Salvador: el ascenso de la nueva derecha". CINAS, 1989. Pero nos atrevemos a sugerir que buena parte de las tesis all sustentadas, son, con las peculiaridades de cada país, susceptibles de ser extendidas a los otros países centroamericanos.

7. Uno de los casos más distintivos de esto to representa el gobierno de Cristiani, para nadie es un misterio que el Departamento de Estado aposto al triunfo de la DC salvadoreha, y que miró con recelo la victoria de ARENA. Pero hoy Bush, Quayle, Baker y Aronson defienden a la gestión arenera de gobierno ante el Senado y la Cámara de Representantes, cuando alli se cuestiona la ayuda que se le brinda.

8. Que esta emergencia de un populismo de derecha, crítico del neoliberalismo y de estilo populachero y demagógico no es sólo una exclusividad centroamericana lo demuestra la candidatura de Errazuriz en las elecciones recientes en Chile, se refleja en parte en el perfil de Pacheco Areco, y en el del peronismo ultramontano.

9. Este hecho es de por sl sintomático, en las décadas pasadas, las visitas de vicepresidentes norteamericanos a América Latina, sirvieron para multitudinarias manifestaciones antiimperialistas. Tal fue el caso on los sesenta y los setenta de las visitas de Nixón y Rockefeller. Hoy en día, a pocas semanas de la invasión a Panamá, Dan Quayle es repudiado por amargados pinochetistas.

10. En el caso de Honduras, los conflictos han sido particularmente fuertes, el secuestro del narcotraficante Ramón Mata Ballesteros los pusieron de relieve y terminaron con la quema del consulado norteamericano. La responsabilidad que al gobierno le cabe en estos sucesos por omisión, fueron puestas de relieve por los nacionales en su crítica al liberalismo gobernante de entonces.

11. Esta última idea, es desarrollada por Sara Gordon. Entrevista con el autor.

12. Al respecto, el muy comentado articulo de Fukuyama es un buen exponente, aun cuando sea previo a las elecciones nicaragüenses. 
13. Con lo anterior, no queremos restar importancia a la enorme dimensión de los procesos de Europa del Este, pensemos que alll no sólo se esta operando un profundo reacomodo del sistema polltico que tiene como común denominador la crítica a lo que podríamos denominar "socialismo real", sino que además se estan modificando las bases del orden de la posguerra. El sólo hecho de la reunificación alemana serla suficiente para sustentar lo anterior.

14. En efecto, el asesinato del padre Ellacuría y sus compañeros, y el secuestro y asesinato de Héctor Oquell demuestran los niveles a que esta dispuesta la ultraderecha para oponerse a cualquier negociación. 